Role of agricultural engineering in environmental and sustainable development FARM MACHINERY AND POWER for the valley and delta areas: 1499 - 1514

\title{
APPLIED APPROACH FOR USE OF JOJOBA OIL AS AN ALTERNATIVE FUEL FOR TRACTOR ENGINE
}

\section{Samy M. younis* Mohamed S. omran $^{* *} \quad$ Mahdy S. mahdy ${ }^{* * *}$ \\ ABESTRCT}

The performance of a tractor diesel engine using blends of jojoba oildiesel fuel compared with diesel was evaluated. Power take-off (PTO) power, specific fuel consumption, and thermal efficiency were examined. The experiments were installed in an experimental completely randomized design arranged in factorial scheme followed by ANOVA analysis and LSD test at the level of 5\% of probability. The results revealed acceptable performance parameters of the tractor engine with blends that containing up to $40 \%$ volume of jojoba oil. From the oil properties and tractor engine test results, it has been established that 20$40 \%$ of jojoba oil can be substituted for diesel without any engine modification. Therefore, the blending of jojoba oil with Diesel is an effective approach to overcome performance losses and any engine problems attributed to high viscosity of neat jojoba oil.

\section{INTRODUCTION}

gypt is recently confronted with the twin crises of energy sources
and environmental degradation. The both of two crises due to
impact of used fossil fuels whereas; the limitation of conventional fuels and growing exhaust emissions pollution. However there is great demand on fossil fuel remarked for the sake of fulfilling energy needs for transport and agricultural sectors. Furthermore the scarcity of conventional fuels coupled with prices fluctuations of diesel fuel conform the second deciding event in the energy issue.

\footnotetext{
*Prof. Dr. Agric. Eng. Dept., Faculty of Agric., Cairo University **Assoc.Prof., Agric. Eng. Dept., Faculty of Agric., Cairo University ***Demonstrator, Agric. Eng. Dept., Faculty of Agric., Cairo University
} 
These triggering factors have spurred scientific community to interest in looking for alternative fuel sources and renewable energy to be supportive for the provision of basic human needs from liquid fuels and also achieve energy security as well as the protecting and preservation of the environment. Therefore the renewable energy including biofuel will have a vital role in achieving the objectives of sustainable development at the global level and in particular Egypt. According to Demirbas, 2008 reported that the biofuel as an alternative fuel source has to maintain good operating engine performance without excessive fuel consumption or engine performance penalties, environmentally acceptable, economically competitive, readily available, and safe in the storage and handling.

The liquid biofuel as one of the recommended alternatives is a fuel produced from bio-origin or biomass may be alcohol and vegetable oils. Some of these fuels can be used directly in the engine while others need to be formulated to bring the relevant properties close to conventional fuels. Vegetable oils have become more attractive recently because of their environmental benefits and the fact that these are made from renewable resources (Demirbas, 2007).

According to Agarwal (2007) mentioned that the utilization of vegetable oils as substitute fuel in diesel engines does not require significant modifications of existing engine hardware due to that vegetable oils have almost similar energy content and cetane number compared to diesel fuel. Also, the wear of vital moving parts of biodiesel-operated engine is substantially lower compared to the diesel-operated engine due to its inherent lubricity properties. Biodiesel and vegetable oil derivative have been researched extensively and found to be a suitable alternative to diesel petroleum (Van Gerpen, et al.2007)

Focusing on the prevailing situation about the main sources of energy for the agricultural sector in Egypt, it's a well-known fact that the density of farm machinery especially tractors, water pumps, power generators and harvesting machines are extensively used in reclamation and cultivation land. As well as grid power is not available in these rural and reclaimed 
areas, where the mechanization of all agricultural operation depends on diesel fuel as source of energy. Therefore oilseed crops can be playing a vital role in fulfilling the needs of farmers from a part of the main energy sources for electrification and agricultural mechanization purposes. Consequently, have to be supported the farmers in capability to produce their requirement of different types of plant oils are available locally in their own farms for achieving a step towards self-sufficiency for Egypt.

Obviously, the uses of non-edible oils as fuel are very economical comparable to edible oils particularly in developing countries because of the tremendous demand for edible oils as food. They are far too expensive to be used as fuel at present and the use of such edible oils to produce biodiesel in Egypt is not feasible because of the increasingly big gap between demand and supply of such oils for dietary consumption.

In Egypt, a variety of non-edible oils likes castor bean, jojoba, and jatropha are available with credible quantities and may be good candidates for use as feedstock in the biodiesel industry or its blends with petrodiesel. Jojoba plant is one of a perennial oil crop that could be successfully cultivated under arid conditions. It grows successfully on newly reclaimed desert lands in Egypt. Jojoba plant is very tolerant of drought/saline, $750 \mathrm{~mm}$ of rain or irrigation is necessary for good yield of seeds, as well as that could be irrigation of treated wastewater. The production of jojoba seeds is about $750-1500 \mathrm{~kg}$ of seeds/feddan according to shrub age and environmental conditions, (Elhelepi, 2007). Jojoba seeds have containing up to $50 \%$ by weight of oil. The oil or liquid wax extracted from seeds is unique non-edible oil, mainly composed of monoesters consisting entirely of a long straight-chain fatty acids and alcohols, and free them from any contains of glycerides. Therefore the jojoba oil is very different from other common characteristics of plant oils. Furthermore no other plant is found to produce liquid of this type as the jojoba plant, (Wisniak, 1977).

Jojoba oil is used in manufacturing some fields of cosmetics, pharmaceuticals and lubricants. Newly, jojoba oil has become one of promising liquid biofuel resource specially, its non-edible oil. Therefore, this study intends to examine and evaluate the use of jojoba oil as 
substitute for diesel fuel in the diesel engine used for operating agricultural mechanization.

\section{Objectives}

This study was conducted to evaluate the overall performance of the tractor diesel engine without any mechanical changes, using jojoba oil and its blends with diesel fuel. The performance parameters of the power take off shaft power, specific fuel consumption and thermal efficiency for tractor fueled with diesel fuel and their blends with jojoba oil were evaluated. To achieve this goal, we sought to:

- Determine the Physical characteristics of jojoba oil and its blends with Diesel fuel standard.

- Evaluate the equivalent PTO power of the tractor engine by using blends of jojoba oil and diesel fuel.

- Evaluate the equivalent specific fuel consumption and thermal efficiency of the tractor engine by using blends of jojoba oil and diesel fuel.

\section{MATERIALS AND METHODS}

\section{1- Blends preparation}

A commercially local available No. 2 Diesel fuel was selected as a compression ignition engine fuel and recommended by the engine manufacturers. Jojoba seeds were purchased from of the experimental station, Faculty of Agriculture, Cairo University where jojoba plant has been grown in this farm on large scale, Jojoba oil was extracted from jojoba seeds by screw squeezing machine. Oil has been utilized in the present work with no additional chemical treatments. The jojoba oil has been filtered and kept in a storage tank inside the laboratory.

Blending of jojoba oil with diesel fuel has been prepared in the laboratory for the purpose of experimental measurements and tractor operation. Different blend ratios have been selected for measurements and evaluation. These blend ratios include $0,20,40,60$ and 80 percent by volume of jojoba oil in a mixture of jojoba oil and diesel fuel. They are referred to as blends jojoba oil with diesel fuel of J20, J40, J60, and J80 respectively. These abbreviations are adopted throughout the present 
study. Specimens of the different fuel blends were totally homogeneous without any signs of mixture separation, deposits or surface reactions after several months of monitoring. Jojoba oil was analyzed to determine Physical characteristics according to American Society for Testing and Materials (ASTM). The physical characteristics of jojoba oil were determined by standard methods were compared with diesel fuel and its blends with diesel fuel.

\section{2- Tractor}

Tractor diesel engine performance tests ware carried out during December 2009 in tractors and agricultural machinery testing station in Alexandria, agricultural engineering research institute (AERI), agricultural research center (ARC). Some technical specifications of the tested tractor are presented in Table 1

Table 1. Technical specifications of the tested tractor

\begin{tabular}{ll}
\hline Model & Helwan 35-IMT \\
\hline Type of engine & $\begin{array}{l}\text { Four stroke, direct injection, } \\
\text { naturally aspirated, air-cooled }\end{array}$ \\
Engine power ,Kw & 25 \\
Rated Engine speed ,rpm & 2800 \\
Compression ratio & $17: 1$ \\
Number of cylinders & 2 \\
Bore $\times$ stroke , mm & $105 \times 125$ \\
Injection pump & In-Line Injection Pump \\
\hline
\end{tabular}

\section{Testing complex setup}

\subsection{The stationary dynamometer}

An AW 2300 PTO dynamometer was used to apply the load and measure PTO performance. The technical specifications of the hydraulic dynamometer are given in Table 2 . The torque and rotational speed were measured on PTO of the tested tractor and consequently the PTO power output can be calculated by the following equation (Goering, 1989):

$$
P=\frac{2 \pi N T}{C}
$$


Where:

P: PTO power, $\mathrm{kW}$

$\mathrm{N}$ : rotational speed of PTO, rpm

T: PTO torque, N.m

$\mathrm{C}: 60 * 1000$

Table 2. Technical specifications of the Hydraulic dynamometer

\begin{tabular}{cc}
\hline Make & USA \\
\hline Model & AW2300 \\
Max. Power, kW & 220 \\
Max. Torque, N.m & 1360 \\
Max. Speed ,rpm & 3500 \\
\hline
\end{tabular}

\subsection{Data acquisition system}

The components selected for the data acquisition system a shown in Fig.( 1) (Daytronic Data PAC Model 10KU analog/digital (A/D) are Capable to convert the voltage signal to the desired SI units. This was accompanied by interfacing with computer Pentium III $750 \mathrm{MHz}$ that has been used in the process to record and save the data files in the program Excel.

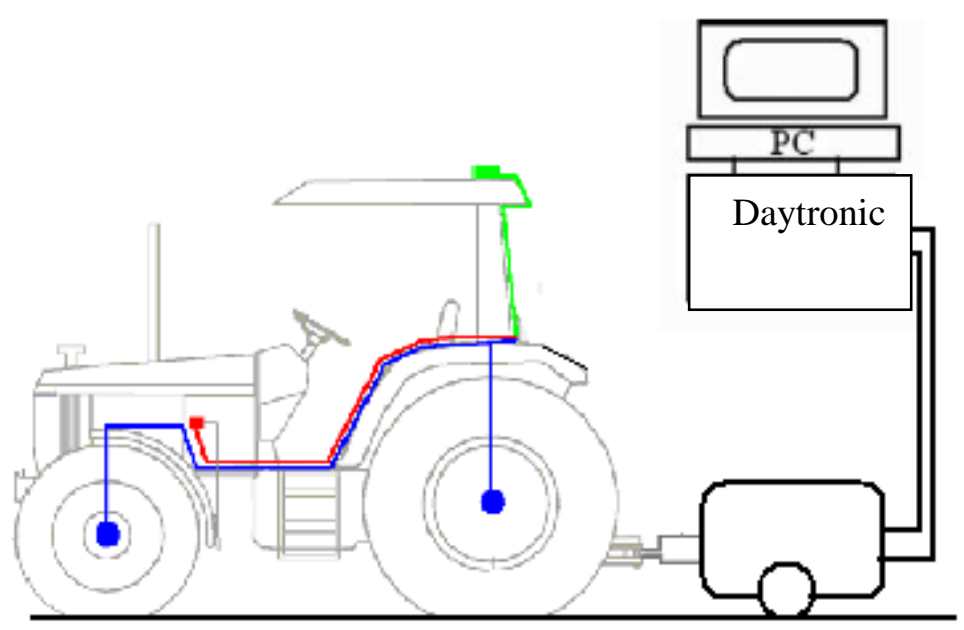

Fig.1. Schematic layout of the tractor test unit communicated with the data acquisition system. 


\subsection{Fuel consumption determination}

Measurement and calculation of fuel consumption for tractor engine was performed on the basis of volume under different PTO loads by using diesel fuel and its blends with jojoba oil .The system depends on the measurement of a given volume of fuel consumed in the operation of the engine during certain period of time where it is determined by using stopwatch. The device shown in Fig.(2)consists of a secondary tank installed on the dashboard, the bottom of this tank is equipped with a control valve that allows the fuel to pass during operation by hose which is connected to a glass bulb tube to show the volume of fuel passing and having capacity of $30 \mathrm{ml}$. Through, the glass tube was connected to the fuel supply system at inlet of the fuel filter directly and being linked to the fuel line return from injectors by transparent hose.

The fuel consumed for each test was measured and time of running each test was recorded, the rate of fuel consumption was calculated using the following equation:

$$
F . C=\frac{V * 3600}{t * 1000}=l . h r^{-1}
$$

Where:

$\mathrm{V}=$ volume of consumed fuel in glass bulb, $(\mathrm{ml})$

$\mathrm{t}=$ Time of running the test, $(\mathrm{sec})$

F.C = rate of volumetric fuel consumption, $\left(\mathrm{L} \cdot \mathrm{h}^{-1}\right)$

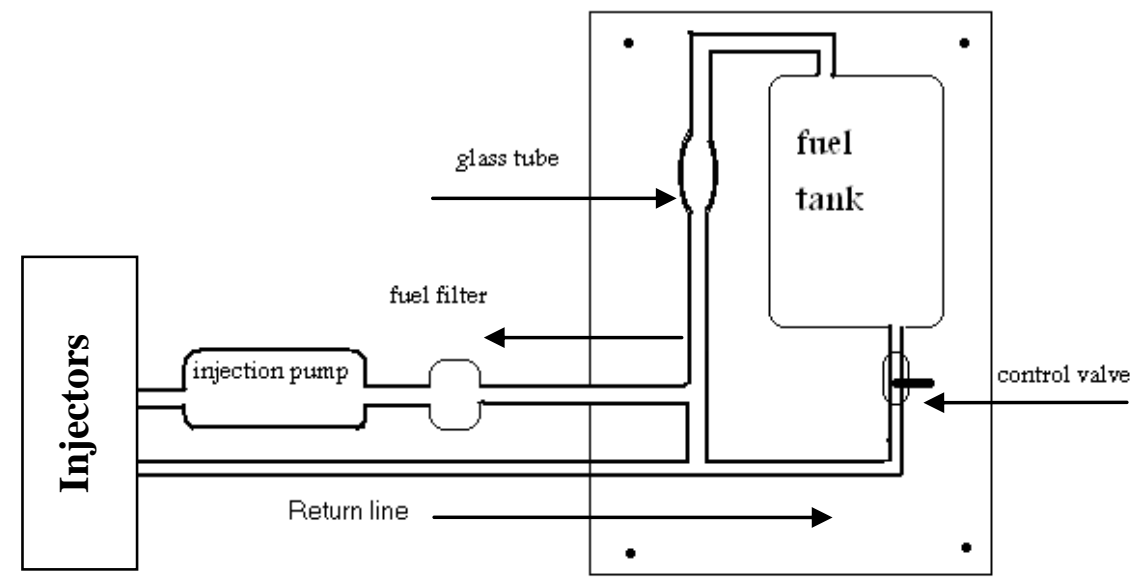

Fig.2. Volumetric fuel consumption apparatus 


\subsection{Calculation of the thermal efficiency}

The thermal efficiency is the ratio between power output and energy released through fuel injection in cylinders of engine. The PTO thermal efficiency of the tractor tested engine was calculated at every applied load levels on PTO shaft. The equation of the PTO thermal efficiency is as follow (Goering, 1989):

$$
\eta_{p t o}=\frac{3600}{S P C \times C . V} \times 100
$$

Where:

$S P C$ : PTO specific fuel consumption $(\mathrm{kg} / \mathrm{kW} . \mathrm{h})$

C.V: calorific value of the tested fuel $(\mathrm{kJ} / \mathrm{kg})$

\section{Experimental set-up and procedure}

The tractor engine is operated using standard diesel fuel, then the tractor engine is operated using the test fuel (percentages of jojoba oil blends with diesel fuel standard), the blends were 20-80, 40-60, 60-40, and 8020 jojoba oil-diesel fuel volume ratios. After completing the tests on each fuel blend, the whole system of fuel was drained and replaced with new blend. After draining and replacement of the fuel filter, the engine was put in operation for ten minutes for avoiding contamination and make sure that the engine fuel system is clean from any residual test fuels. Readings obtained from the values of torque, rpm and time of fuel consumed for a particular test case are recorded after a sufficiently time that ensures stabilizing performance of the tractor engine. The ambient environmental conditions were monitored to ensure that the tests were in compliance with the OECD Tractor Test Codes (OECD, 2009).

\section{Experimental design}

The experimental design was carried out to determine torque, power, specific fuel consumption, and thermal efficiency at different values of PTO load in function of the rotational speed, for each of tested fuel. The maximum power, the transmission system was fired up and the tractor was put at full throttle, between the range of $\mathbf{7 0 0} \mathrm{rpm}$ (PTO), which represents the void of power and $\mathbf{4 3 2} \mathrm{rpm}$ (PTO) value that corresponds 
to the shutdown of the engine. Five levels of rotation with an interval of $65 \mathrm{rpm}$ for the tests were $635,570,505$ and 440 , or $90 \%, 81 \%, 72 \%$, and $62 \%$ of maximum speed, respectively. The experimental design was a completely randomized design (CRD), in factorial scheme $5 \times 4$, involving five types of test fuel and four levels of rotation of the engine, with four replicates. The treatments were pure diesel fuel standard, and jojobadiesel fuel blends. The present data were subjected to analysis of variance (ANOVA) and the least significant difference test (LSD) at level of $5 \%$ of probability was performed using M.STAT computer program.

\section{RESULTS AND DISCUSSIONS}

\section{Physical and thermal properties of jojoba oil}

The fuels (Diesel, jojoba oil and it is blends with diesel) were analyzed for several physical and thermal properties and results are given in Table 3. The physical properties are proved to be very sensitive to the blend ratio. The viscosity was measured for different blends of jojoba oil with diesel fuel to find out the effect of blending on viscosity. The blending of jojoba oil with diesel seems to be an effective way to improve the blend viscosity a shown in table 3 . It is clear has been seen from table 3 that the kinematic viscosity of jojoba oil at $40 \mathrm{C}$ is $25.20 \mathrm{cSt}$ as compared to only $4.20 \mathrm{cSt}$ for diesel fuel at the same temperature. The viscosity increases with the increase of jojoba oil percentage in the blend mixture. It is also seen from table that the each of $20 \%$ and $40 \%$ blend ratios of jojoba oil, the value of the viscosity of these blends are very close to the corresponding value of diesel fuel. Therefore, thus blends containing to $20-40 \%$ of jojoba oil can be used as engine fuel without preheating and any engine modification. The observed values of flash point for jojoba oil and diesel fuel are 295 and $76{ }^{\circ} \mathrm{C}$, respectively. The flash point temperature is critical from a safety viewpoint. Blending of jojoba oil with diesel fuel reduces the value of the flash point of the blend. However, the flash point of the different blend ratios is relatively higher than that of diesel fuel. The energy content or net calorific value of jojoba oil is about $12 \%$ less than that of diesel fuel on a mass basis due to 
the oxygen content in the molecules of jojoba oil. Therefore increasing proportion of jojoba oil in blend decreases the calorific value of the blend. The jojoba oil is free from ash content which indicates that it does not contain any metallic. Therefore, jojoba oil is not a corrosive material and it has no sulfur. Hence, using the jojoba is possible to reduce the engine wear.

Table 3.Physical and thermal properties of jojoba oil and its blends relative to Diesel fuel

Property

Blend of jojoba oil (J) and diesel fuel(D)

methods

ASTM

$100 \%$

$20 \% \mathrm{~J}-40 \% \mathrm{~J}-60 \% \mathrm{~J}-\quad 80 \% \mathrm{~J}-$ Jojoba

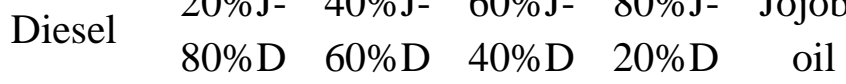

\begin{tabular}{cccccccc}
\hline $\begin{array}{c}\text { Density } \\
25^{\circ} \mathrm{C}\left(\mathbf{g . c m} \mathbf{-}^{\mathbf{3}}\right) \\
\text { Kinematic }\end{array}$ & D-287 & 0.831 & 0.833 & 0.841 & 0.848 & 0.853 & 0.863 \\
$\begin{array}{c}\text { viscosity at } \\
40{ }^{\circ} \mathrm{C}(\mathbf{c S t})\end{array}$ & $\mathrm{D}-445$ & 4.20 & 5.12 & 8.70 & 12.40 & 16.33 & 25.20 \\
$\begin{array}{c}\text { Calorific value } \\
(\mathrm{MJ} / \mathrm{kg})\end{array}$ & $\mathrm{D}-240$ & 43.65 & 41.34 & 40.45 & 39.43 & 39.15 & 38.45 \\
$\begin{array}{c}\text { Flash point }\left({ }^{\circ} \mathrm{C}\right) \\
\text { Pour point }\left({ }^{\circ} \mathrm{C}\right)\end{array}$ & $\mathrm{D}-93$ & 76 & 75 & 78 & 83 & 96 & 295 \\
$\begin{array}{c}\text { Ash content } \\
(\% \text { by weight })\end{array}$ & $\mathrm{D}-482$ & -6 & -4 & -3 & -3 & 4.55 & 7.15 \\
\hline
\end{tabular}

\section{Effect of jojoba oil-Diesel blends ratio on engine performance}

The effect of the jojoba-diesel blends ratio on the engine performance has been studied by using blends of 20\%, 40\%, 60\% and $80 \%$ jojoba oil with diesel fuel as engine fuels. PTO of tractor performance parameters have been measured using jojoba blends and compared with the basic engine performance using $100 \%$ diesel fuel at wide range of loads and rotational speed according to official OECD. The obtained data were analyzed and 
processed statistically .The summary of the analysis of variance, the average values of PTO power and fuel consumption in relationship to the rotations and loads on PTO shaft for the fuels tested are discussed as follows.

\subsection{P.T.O Power}

The results of the test for the average PTO power relation with the tested fuel blends are presented in Table 4. The results of averages power for blends of jojoba oil are statistically different as diesel fuel percentage changes.

Table 4. Average PTO power in relations with the fuels blends.

\begin{tabular}{cc}
\hline Test fuel & Average power $(\mathrm{kW})$ \\
\hline Diesel fuel & $20.52 \mathrm{a}$ \\
20\% jojoba oil & $20.20 \mathrm{a}$ \\
40\% jojoba oil & $19.65 \mathrm{~b}$ \\
$60 \%$ jojoba oil & $18.86 \mathrm{c}$ \\
80\% jojoba oil & $18.43 \mathrm{~d}$ \\
\hline
\end{tabular}

Different letters indicate significant different between average values

The PTO power output slightly decreases with the increase of jojoba oil percentage in the blends. It should also be mentioned that the lowest remarkable difference has been observed in power using J20 and J40 as compared to diesel fuel. Since the calorific value of J20 is relatively lower than that of diesel fuel. This may be an indicator of a relatively more complete combustion in J20. Which can be justified by the fact that the molecules of jojoba oil possess oxygen in its chemical composition, what improves the burning during the combustion, since has greater availability of oxygen for the process, making with that $\mathrm{J} 20$ acts as oxidation catalyst in this case. Although, the increase of jojoba oil percentage in the blend as high as $60 \%$, but the PTO power was decrease due to rise the decrease in the calorific value of the blended fuel with the increases of jojoba oil percentage in the blend as well as the higher viscosity of blends for J60 and J80. Thus result in poor atomization and combustion for these blends accompanied by loss of power generation. The interactions between the power and fuel blends are shown in Fig. (3) 
point to a superior performance of the tractor engine in the entire power curve, also presenting, the biggest value of power amongst all the fuels, being of $24.30 \mathrm{~kW}$ at $570 \mathrm{rpm}$ in the PTO using the diesel fuel and subsequent $\mathrm{J} 20$ and $\mathrm{J} 40$ power being of 23.52 and $22.60 \mathrm{~kW}$ respectively that was at the same rotational speed.

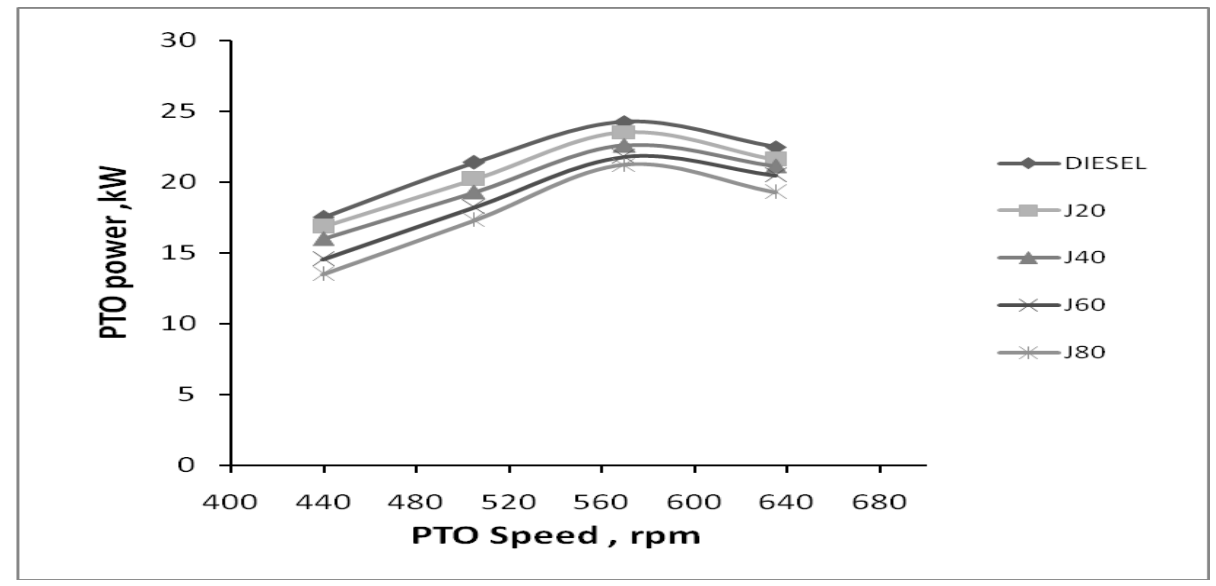

\section{Fig.3. The variation of average PTO power in relation with PTO speed for diesel and different blends of jojoba oil}

\subsection{PTO Specific fuel consumption}

The Specific fuel consumption is calculated by taking the mass flow rate of fuel in grams per second and dividing it by the power produced by the engine in kilowatts. The variations of specific fuel consumption with PTO loads using blends of J20, J40, J60, and J80 jojoba oil with diesel fuel as compared to $100 \%$ diesel are shown in Fig. (4) The PTO specific fuel consumption slightly higher with the increase of jojoba oil percentage in the fuel blend which may be attributed to the lower calorific value of the blended fuel with the increase of jojoba oil percentage in the blend compared to diesel fuel. The both of blend ratios $\mathrm{J} 20$ and $\mathrm{J} 40$ fuel as the detained of the close to specific fuel consumption in all the band of rotation of PTO as compared to diesel fuel. While using ratios of J60 and J80 resulted in significant difference when compared to diesel fuel. Analyzing the results of specific fuel consumption relations with the PTO loads revealed that the diesel fuel had the lowest average 
value 294.43 [g. (kW.h) ${ }^{-1}$ ]. The jojoba oil 20\% showed, 314.7 [g. (kW.h) ${ }^{-1}$ ] which the nearest to diesel fuel, therefore J20 blend is the best result among ratio blends.

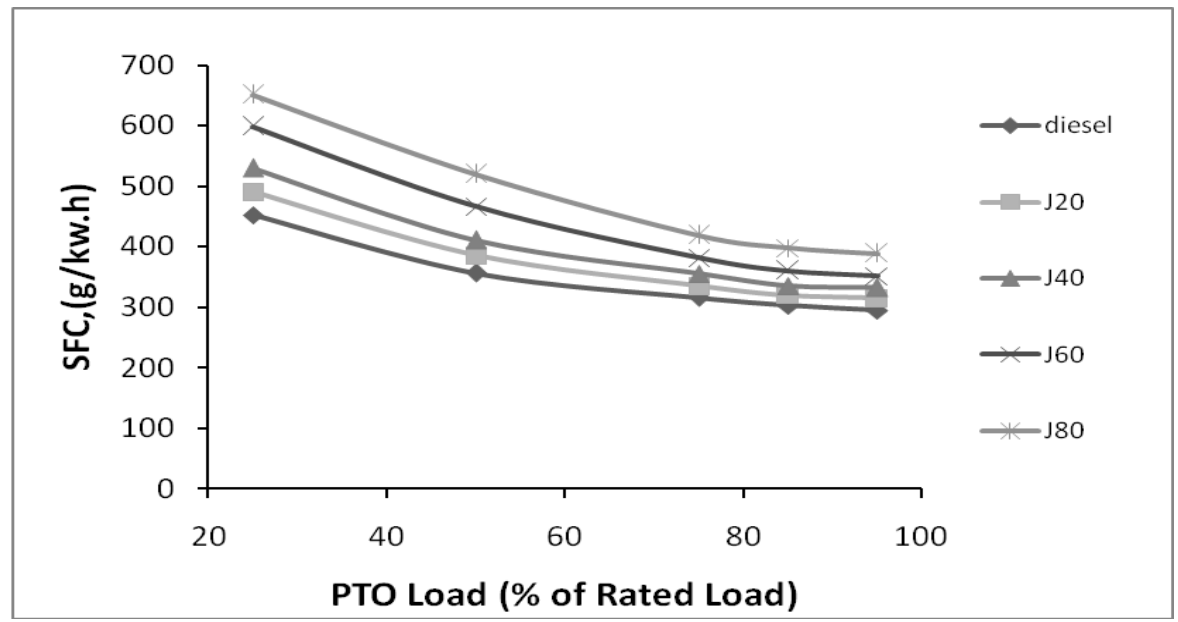

Fig.5. The variation of specific fuel consumption in relation with percentage loads for diesel and different blends of jojoba oil

\subsection{Thermal efficiency}

The variations in the estimated of the thermal efficiency are graphed in Fig. (5) where a slight decrease by increasing of jojoba oil percentage in the fuel blend is observed. The thermal efficiency of the engine found in $20 \%$ and $40 \%$ jojoba oil blends showed similar thermal efficiency with diesel fuel. However, thermal efficiency decreased with further addition of jojoba oil to diesel. The possible reason improved thermal efficiency for J20 and J40 were due to the oxygen atom present in the blends molecules improves the combustion characteristics. Since these blends have act as oxidation catalyst is making effect redemptive for the relatively lower calorific value of the jojoba oil blends as compared to diesel fuel. Thus result in more complete combustion and improving the thermal efficiency for the blends J20 and J40. 


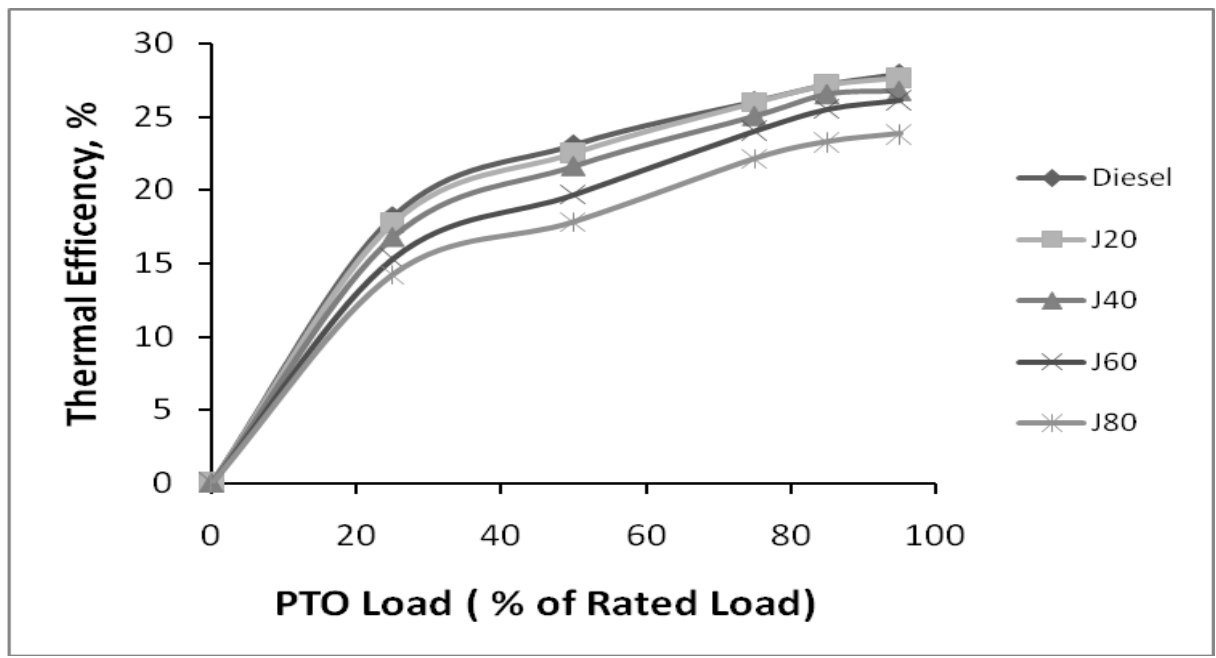

Fig. 6. The Variation of thermal efficiency in relation with percentage loads for diesel and different blends of jojoba oil

\section{COCLUSION}

\section{The results obtained allow the following conclusions}

1. The physical properties of jojoba oil have indicated a good potential of using jojoba oil as an alternative fuel for Diesel engine. Therefore the jojoba oil will be a very promising alternative fuel for diesel engine for agricultural applications.

2. Blending of jojoba oil with diesel has shown to be an effective approach to reduce engine problems attributed to high viscosity of jojoba oil. Hence, using blended jojoba oil is an attractive alternative fuel because of the shortage of diesel fuel and jojoba oil is produced locally.

3. It can be adopted to use jojoba-diesel fuel blend ratio as high as $40 \%$, the results were very close to diesel fuel properties. The $20 \%-40 \%$ blends, have given very similar performance parameters of the power, fuel consumption and thermal efficiency. Hence, using this blend will be substitute diesel fuel in diesel engine without any engine modification and get on engine performance satisfactory.

\section{REFERENCES}

Agarwal, A. K. 2007. Biofuels (alcohols and biodiesel) applications as fuels for internal combustion engines. Progress in Energy and Combustion Science, 33: 233-271. 
Book No. 7. Michigan. 539 p.OECD Standard codes for the official testing of agricultural and forestry tractors. 2009. Organization for Economic Co-operation and Development. <http://www.oecd.org>, Accessed September 10, 2009.

Demirbas, A.2008. Biodiesel: a realistic fuel alternative for diesel engines. Published by Springer-Verlag London Limited, 214 pp

Demirbas, A. 2007. Importance of biodiesel as transportation fuel. Energy Policy, 35: 4661-4670.

EIhelepi, M. 2007. Economic feasibility study of using treated wastewater in irrigation. Published by United States Agency for International Development, prepared by International Resources Group, Report No. 33, 68pp

Goering, C.E.1989. Engine and Tractor Power. St. Joseph, Michigan: published by ASAE . 404 pp

Wisniak, J. 1977. Jojoba oil and derivatives. Prog. Chem. Fats Lipids, 15:176-218.

Van Gerpen, J.H., C. L. Peterson, and C.E. Goering.2007. Biodiesel: An Alternative Fuel for Compression Ignition Engines. ASABE Annual International Meeting for Agricultural Equipment Technology Conference, 11-14 February 2007, Paper Number: 913C0107. Lecture No 31, 1-22 pp

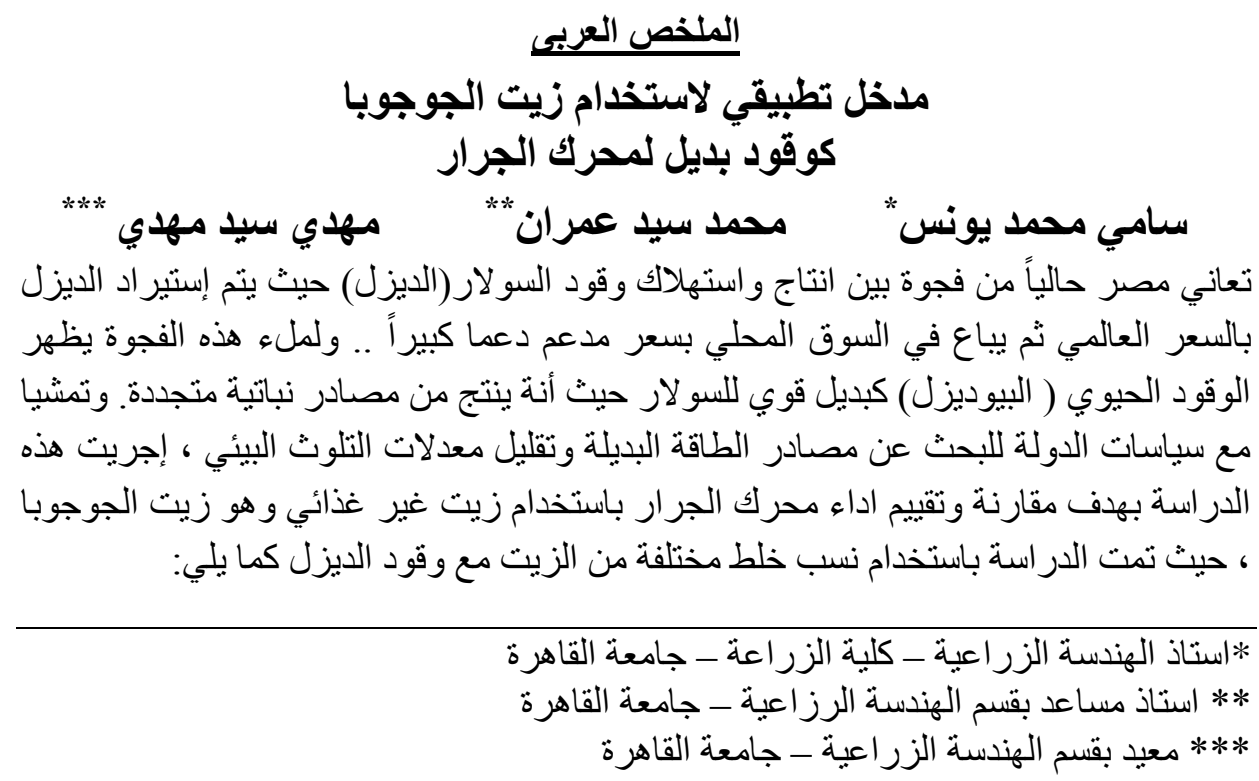




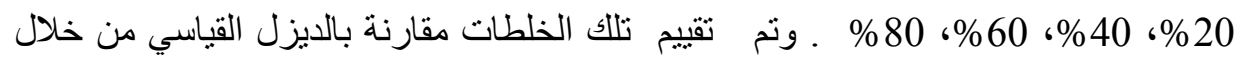

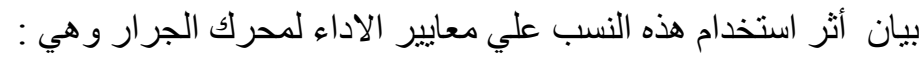

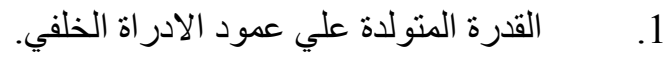
2. 3.

وكانت أهم النتائج المتحصل عليها التها في هذه الدراسة كما يلي :

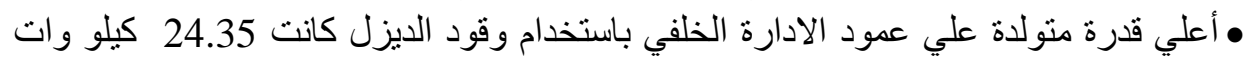

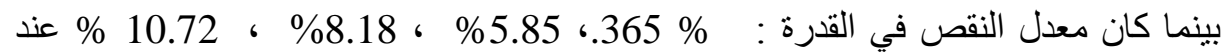

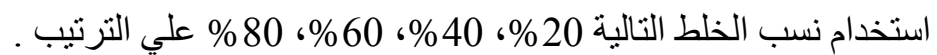

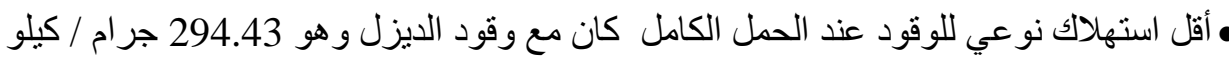
وات . ساعة. بينما كان مع نفس نسب الخلط كالتالي جرام / كيلو وات. ساعة على علي الترتيب.

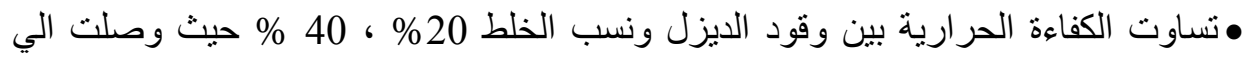

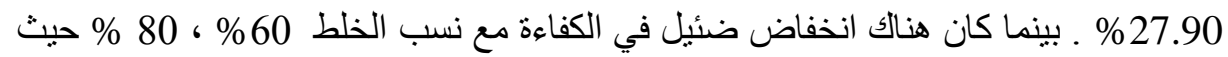
كانت 26.13 \%، 24 \% علي الترتيب .

الخلاصة والتو صية :يمكن التوصية باستخدام نسب خلط تتراوح 20\% الي 40\% من زيت الجوجوبا حيث ان هذه النسب حققت اداء جيد لمحرك الجرار وفاقد ضئيل في القدرة والوقود لئل

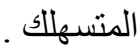

